Flashbulb Memory and its Relationship with The probabilistic Approach

\author{
Riadh Aziz Abbas, PHD \\ College of Arts - Al-Mustansiriya University \\ drreathazz@gmail.com
}

DOI: $\underline{\text { 10.31973/aj.v3i138.1091 }}$

Abstract

The present Research aims at knowing the following;

- the flashbulb memory among the research sample.

- the probabilistic Approach among the research sample.

- correlation Between flashbulb memory and the probabilistic Approach among the research sample.

In sample of the test consists of (180) university Lecturers. Where males are (90). females are (90). the order to achieve the objectives of this research the has constructed two scales

The first is used for measuring the flashbulb memory and the second for measuring the probabilistic Approach.

The Research Reached the following results:

- The university Lecturers characterizes with the flashbulb Memory.

- the university Lecturers used weakly the probabilistic approach.

- there is an inverse Relationship between the flashbulb Memory and the probabilistic Approach.

Finally in the light of Results the Research has arrived at a number of Recommendations and suggestions.

Keywords: (Memory, Flashbulb Memory, Approach, Probabilistic, Probabilistic Approach) 


\title{
ذاكرة الوميض وعلاقتها بالمنهج الاحتمالي
}

\author{
د. دياض عزيز عباس \\ كلية الآداب - الجامعة المستنصرية \\ drreathazz@gmail.com
}

(مُلَخََّصُ البَحثث)

بروم البحث الحالي التوصل الى الاهداف الآتية: -

1- معرفة ذاكرة الوميض لاى عينة البحث.

r- بعرفة المنهج الاحتمالي لاى عينة البحث.

r- معرفة العلاقة بين ذاكرة الوميض والمنهج الاحتمالي لدى عينة البهن البحث.

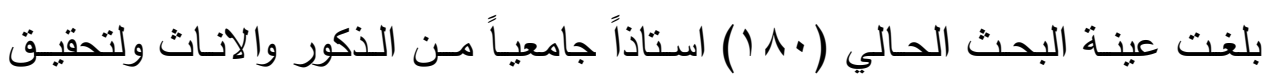

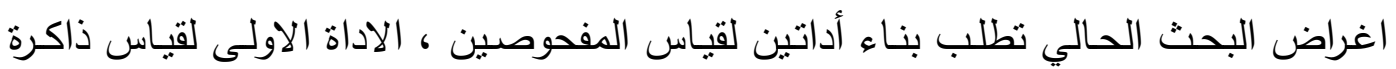

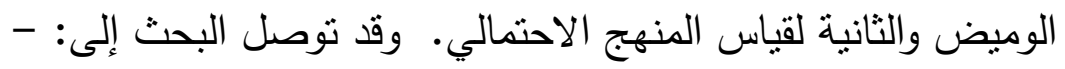

1- ان اساتذة الجامعة لديهم ذاكرة وميض جيدة.

r- ان اساتذة الجامعة يتبعون بشكل ضعيف المنهج الاحتمالي.

r- ان هناك علاقة عكسية بين ذاكرة الوميض والمنهج الاحتمالي.

وفي ضوء نتائج البحث الحالي خرج الباحث بعدد من النوصيات والمقترحات.

الكلمات المفتاحية: (الذاكرة، ذاكرة الوميض، المنهج، الاحتمال، المنهج الاحتمالي)

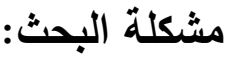

تعدُّ ذاكرة الوميض طريقة واسلوب للاحتفاظ بالذكريات وتفصيلاتها التي تضم كل ما

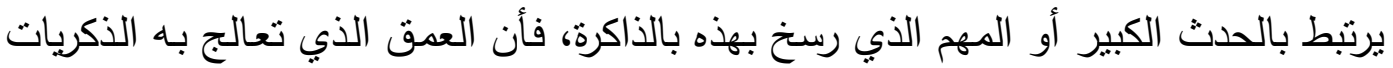

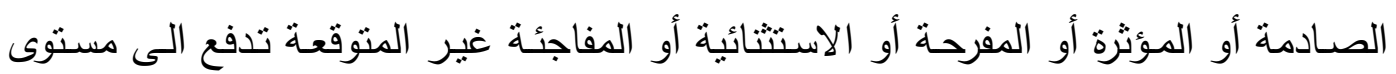

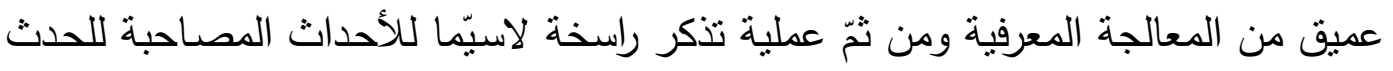

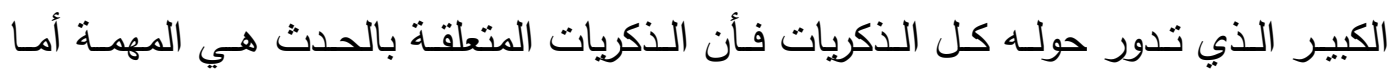

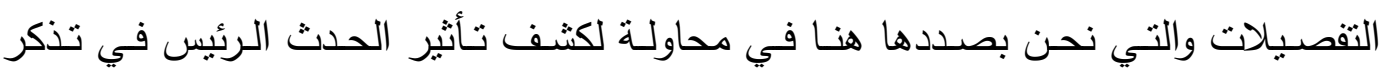
تفصيلات الاحداث المصاحبة أو المتزامنة معه. (Talarico \& Rubin, 2009, P.189)

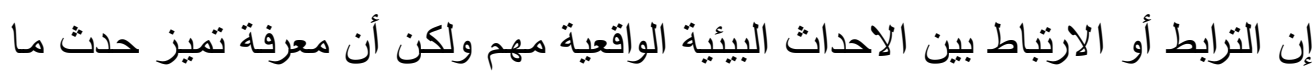
في هذا الثأن وتأثيره الواقعي الحقيقي في احداث الفرق هو شيء جديد الاحت ومميز للإراسـة. كنللك يمكن الاشتارة الى أن التفكير يتخذ هو الاخر اتجاه متعلق بالذكريات ونوعها وشدنها

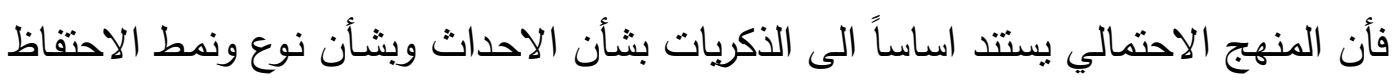


وكيفية استخدامها فيما بعد، فأن الافراد عادةً يصدرون احكاماً حول الاحداث في البيئة من خـلال مـا يحملون مـن معرفـة او خبرات بثـأن الاحداث السـابقة وليست مـن فحص متأن للأحداث وتتبع الاحتمـالات وانما احكام فكربـة قائمسة على معالجـة ذهنبة تتسم بالاحتمالية غير المنطقية. (Wason, 2001, P.63) وعليـه فأن البحث الحسالي بصدد الاجابـة عن التسـاؤلات حول هل أن اعتمـاد المنهج الاحتمالي قائم اساساً على نمط الذاكرة الومضية؟ وهل أن هذا النمط من الذاكرة يمد النظام المعرفي بذكريات ذات طبيعة حدثيـة وليست ذاكرة متعلقة بحيثيات أو تسلسل أحداث قبل الحدث المؤثر؟ وهل أن المنهج الاحتمالي يقوم على اساس اعتمـاد اسلوب معالجة معرفية

يتضمن الذاكرة الومضية؟ أهمية البحث والحاجة اليه: -

إن تصوراتتا لعمل الذاكرة مازال في طور التطور ليس فقط في مجال الاستفادة المثلى منها ولكن حتى في مجال آلية العمل ونمط الترميز والاعتماد من عدم الاعتماد للذكريات

(Dividson, 2002, P.99)

قام كل من براون وكوليك عام 1977 بدراسـة معمقة حول الذاكرة الومضية أو ذاكرة الوميض إذ قاما بسؤال الامريكيين عن مجموعة حوادث وقعت قبل عدة سنوات، والغاية من القياس ليس الاحداث ذاتها وانما الاحداث المصاحبة لها والتي هي احداث اعتيادية عادة لا يختزنها الفرد ويرمزها فهو لا يسعى الى استعادتها لاحقا لعدم جدوى ذلك. كذللك قام كل (من نيسر وهارستس عام ب99 ( ) ). بدراسـة حول ذاكرة الوميض وكان السؤال حول انفجار مكوك الفضاء جالنجر وقد اظهر الامريكان وبنسبة . ^\% انهم تذكروا كل الاحداث والتفصيلات التي حدثت في وقت سماعهم بالحادث. كذلك قام كل من دافيدسون وغليسك (Davidson\& Glisky, 2002) بدراسة حول احداث وفاة امبرة ويلز ديانـا في بـاريس وقد نوصـلا إلى النتائج نفسها نقريبا ان النسبة الاكبر من المفحوصين كانت تثذكر التفصيلات بشكل كبير . وقام كل من تالاريكو وروبين (Talarico \& Rubin، Y. . T بدراسة حول علاقة ذاكرة الوميض بقرات الترميز لدى العينة وقد كانت الترميزات جيدة استتاداً إلى نمط الحدث وقوة الحدث ومستوى علاقة الحدث أو ذاكرة الوميض بحياة الافراد ومستقبلهم كما يتوقعون هم.ويشير كل من براون و وكوليك Mrown \& Kulik , 1977 ( 1977 ) إلى أن الافراد يحتفظون بالأحداث المصاحبة أو المتزاوجة مع الحدث الاهم أو الأكبر وهم بذللك يصنعون علاقات بين الاحداث اليومية الاعتياديـة والتي لا يجري تذكرها عادة(الجلوس في حديقة المنزل ) أو رؤيـة أحـد الاصـدقاء في الثـارع بالصـدفة وبين الحدث المهـم وهذه العلاقـة 
الافتزراضية بين العناصر هنا ربما تشير إلى نمط من التقكير وهذا النمط بسمى بالتفكير

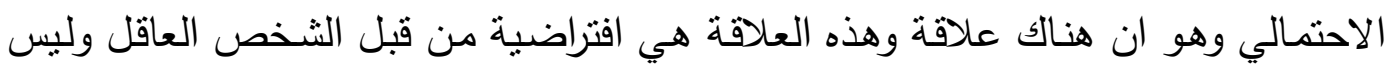

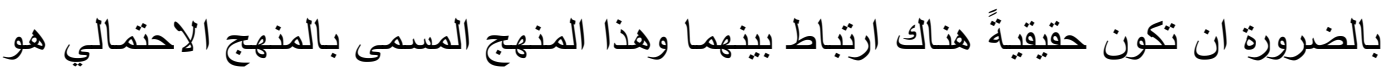
أن الاطر العامة للحكم هي افتراضية ناتجة عن الذاكرة او الخبرات في الذاكرة وهو استخلال

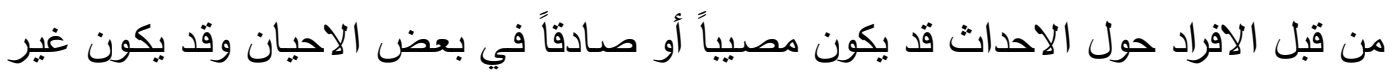
دقيق في احيان اخرى.

إن توخي الدقة في الاحداث اليومية الروتينية قد لا يكون مؤثرا تماما في حياة الفرد وتقدمه في الحياة ولكن إذا كانت الاحداث والحكم هنا متعلق بالعمل أو بالأسرة أو بالمدينة

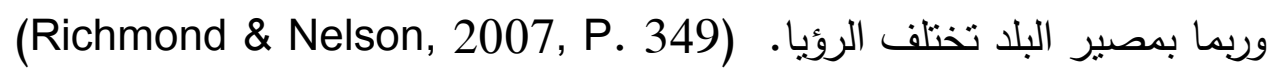
فقد لاحظ شانر واكسفورد عام 1991 (Oaksford \&Chater, 1998) ان الافراد يقيمون الاحداث على وفق تصورهم هم فقد عرض على مجموعة من الافراد البالغين صورة لزميلهم وهو يعطس ويرشح وقد طلب اليهم الافتراض حول الفيدو عن سبب العطاس والرشح

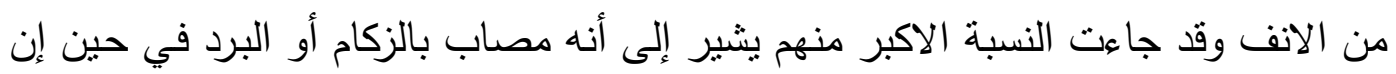

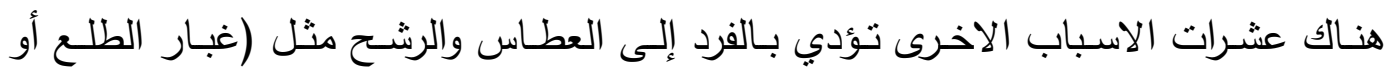

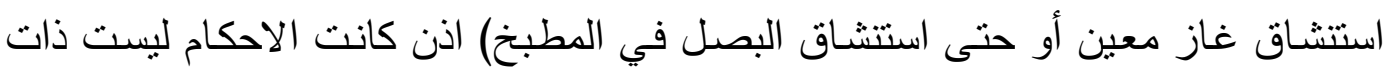

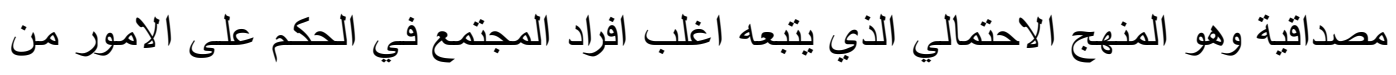

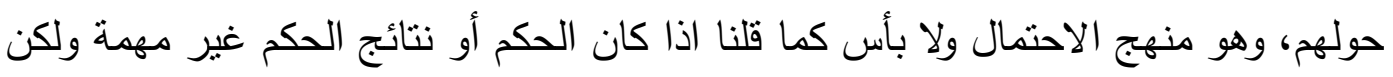

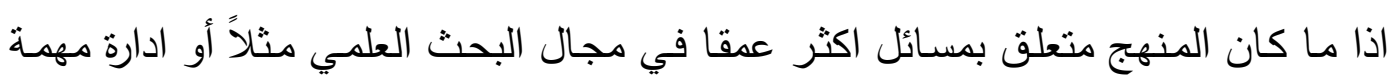

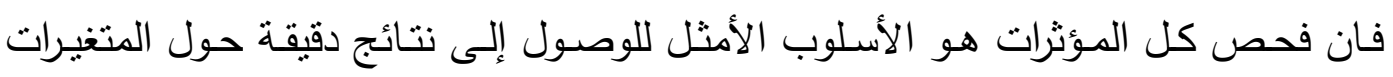
والاحكام بشأنها. في دراسة قام بها (Wason, 2001) التفصيلات ظهر ان مدراء الاقسام اتخذوا على الألى

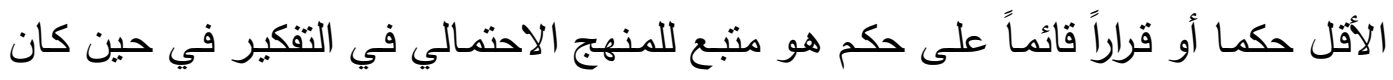

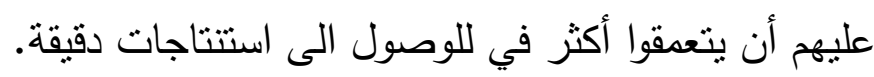

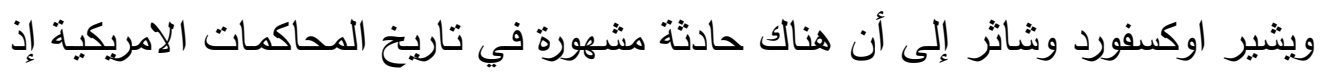

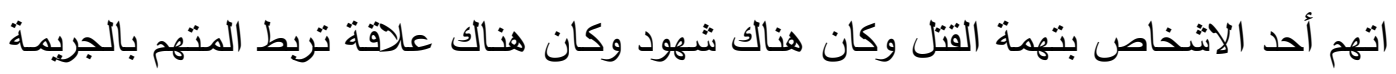

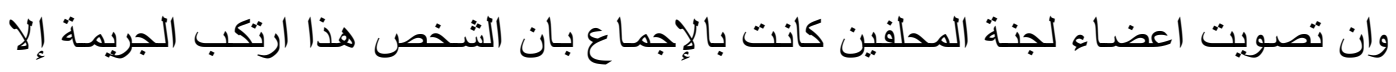

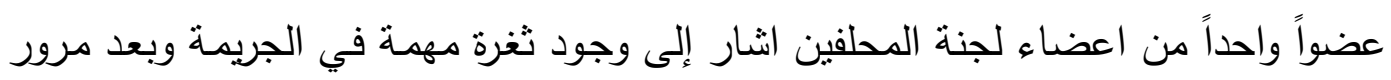
ساعات طويلة من النقاش وعبر التفكير المضني وفحص الادلة مرة اخرى وسؤال الثهود مرة اخرى تغير الحكم إلى براءة المتهم. (Wason, 2001, P.68) 
اذن المنهج الاحتمـالي قد يكون خطراً إلى مرحلـة تهديد حياة الناس أو مصـالحهم الاقتصادية وعليه فان البحث الحالي هو محاولة لتحري علاقة جديدة على المستوى النظري الأكاديمي وكذللك تحري علاقة جديدة عن المستوى الحياتي الواقعي إذ إن كل من ذاكرة

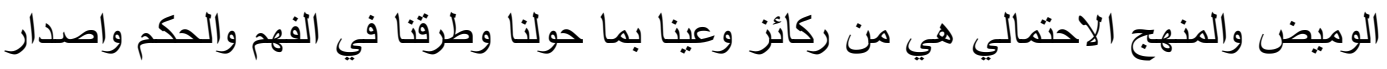
الاحكام حول القضايا المحيطة بنا.

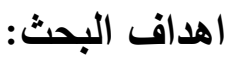

$$
\text { يهدف البحث الحالي الوصول إلى: }
$$

1 - معرفة ذاكرة الوميض لدى عينة البحث. r- بعرفة المنهج الاحتمالي لدى عينة البحث. r- معرفة العلاقة الارتباطية بين ذاكرة الوميض والمنهي لهئه الإحتمالي لدى عينة البحث.

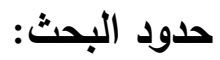
يتحدد البحث الحالي بتدريسيي جامعة المستصرية ممن كانوا قد حصلوا على شهادة

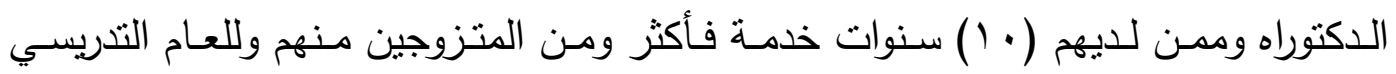
$. r \cdot 19-r \cdot 11$ تحديد المصطلحات: اولا: - ذاكرة الوميض: Flashbulb Memory: 1- تعريف بروان وكوليك: (Brown \& Kulik)

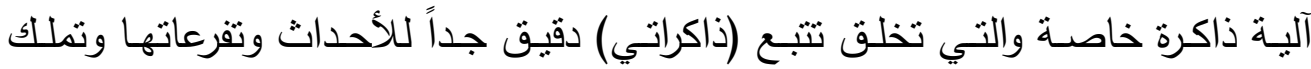
مناعة من عمليات النسيان العادية. (Brown \& Kulik, 1977, 74) r r تعريف دافيسون وكليسك (Davidson \& Glisky) نمط من الذاكرة الخاصة والتي تمسك احداثاً تفصيلية في أثناء عملية المعالجة الحرجة وتتميز بأنها طويلة الامد. (Davidson \& Glisky, 2002, P. 99) r- تعريف بادلي (Baddeley)

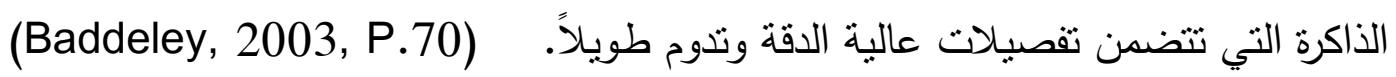
وقد تبنى الباحث تعريف (براون ووكوليك) لاتفاقه مع منهج وطريقة القياس والتفسير للنتائج، أما التعريف الاجرائي: فهو الدرجة الكلية التي يحصل عليها المستجيب من جراء إجابته على مقياس ذاكرة الوميض المعد لهذا الغرض. 
ثانياً: المنهج الاحتمالي: Probabilistic Approach:

(Oaksford \& Chater):1991 تعريف اوكسفورد وشثاتر

تفكير غير ممنهج وغير منطقي وغير متبـع للقوانين المنطقيـة للتوصل للأحكام.

(Oaksford \& Chater, 1998, P. 153)

r

تفكير قائم على اعتماد المؤشرات المتاحة والواضحة أمام الفرد للتوصل للحكم من دون

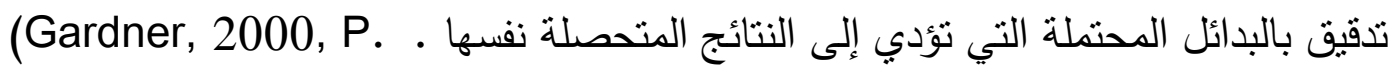

r- 2001 (Wason) تعريف واستون

المنهج القائم على الاحكام المسبقة المبنية على الخبرات من دون مراعاة المعطيات

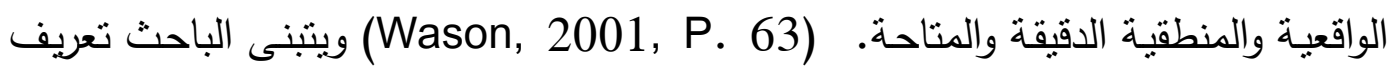
اوكسفورد وشاتر لاتفاقه مع القياس وتفسير النتائج.

أما التعريف الاجرائي: فهو الدرجة الكلية التي يحصل عليها المفحوص من جراء إجابته

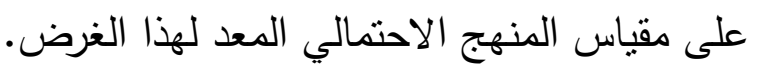

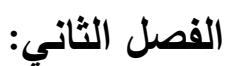

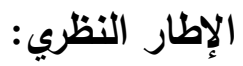

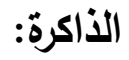

تعد دراسة الذاكرة من المواضيع الواسعة الاهتمام في مجال علم النفس بشكل عام وعلم

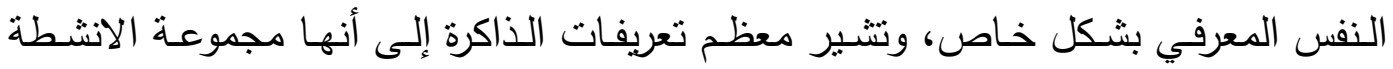

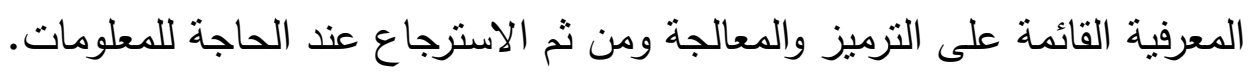

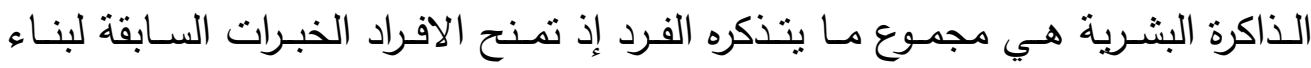

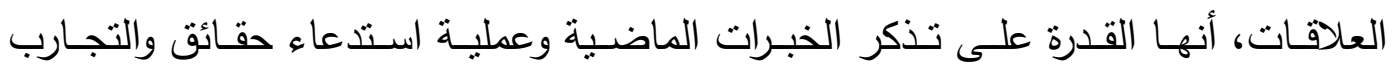

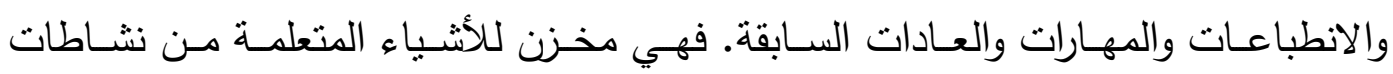
وخبرات. (Martin, 1993, P. 176) نماذج الذاكرة: هناك عدة نماذج للذاكرة ومن أهمها: نموذج أنكينسون وشيفرين (Atkinson- Shiffrin Moodel 1968): وهو من أكناء أكثر

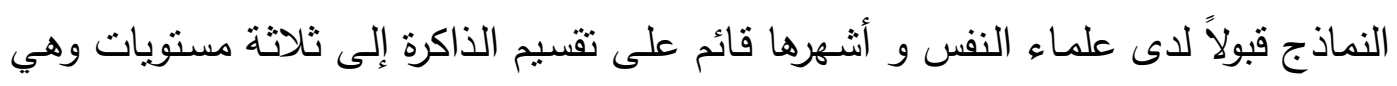

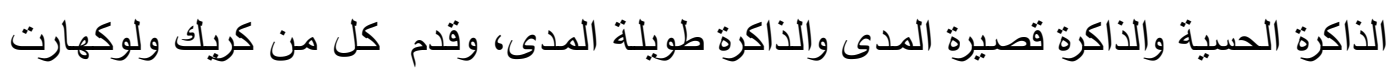
(Craik \&Lockart, 1973) طبيعة الاحتفاظ بالمعلومات فمن المعالجة البسيطة (الحسية) إلى المعالجة العميقة (الدلالية) 
تتوزع مهام الذاكرة فأنه ليس هنالك فرق بين قصيرة المدى وطويلة المدى فليس من هيكل للذاكرة، وهناك أنموذج برودبنت (Broadbent Model, 1970) وبعتقد برودبنت أن هناك نوعين من الذاكرة الذاكرة قصيرة المدى تتعامل مـع الاحداث اليومية والثانية الذاكرة طويلة المدى تتعامـل مـع تأريخ الفرد لمدد طويلـة، وهنـاك أنموذج ووف ونـورمن وانمـوذج بـادلي

وأنموذج وبرانسفورد وغيرها. (Martin, 1993, P.177)

ذاكرة الوميض:

تعرف ذاكرة الوميض بأنها الذاكرة التي نستمد قوتها وبقائها ليس من نوع ونمط وعمق وأهميـة المـادة التي يتم تـكرها، (وهو المعروف عن الذكريات وطريقـة واسـلوب احتفـاظ الانسان بها). وانما تعتمد لحظة حصول التذكر ومدى عمق المعالجة وأهمية الوضـع الذي جرى بـه الحصول على المعلومات وليس نوع ولا اهمية المعلومات كما أسلفنا. فعلى سبيل المثال بمكن السؤال "هل تتذكر اللحظة التي حدث فيها اصطدام الطائرتان ببرجي التجارة العالمي عام I . . ب في نيويورك في الولايات المتحدة". ومن المرجح أن يكون عند ، ^\% من الناس تذكر الموقف والمكان الذي كانوا فيه على الرغم من احتمالية عدم أهمية المكان والحدث حينما علموا بالهجوم اذن الاهمية هنا ليست للحدث المتذكر (وهو حدث بسيط قد يحدث يومياً) وانما لما رافقه من أحداث، الناس كانوا يجلسون في الحديقة وهم يقومون بذلك يوميا تقريبا وعليه فان تذكرهم لذلك اليوم والاحداث التي كانت قبل وبعد معرفتهم بـالهجوم مرتبط بالحدث الصـادم وليس بأحداث ذلك اليوم

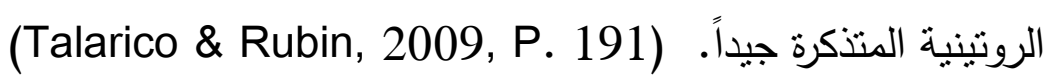
وعليه يبدو ان نوع الصدمة وشدتها التي تحدث نوعا من التتبيه الثديد لدى الفرد هو ما روا يميز الخبر ومن ثُّ فأن الاحداث الرتيبة أو الاعتيادية التي تتخلل ذلك الموقف أو ذلك اليوم

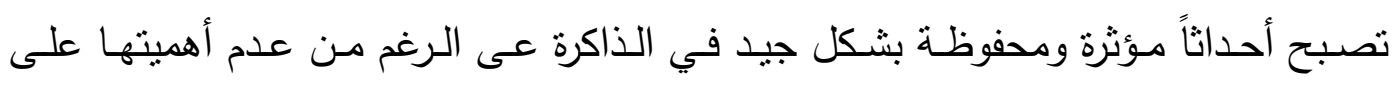
الاطلاق على مستوى الاحداث. وقد كان براون وكوليك 1977: اول من درس هذا النوع من الذاكرة. ويشيرا هنا إلى أن الذاكرة تعمل على وفق نظام مترابط اي اننا لا نستطيع أن نفصل حدثاً عن آخر أو ذاكرة

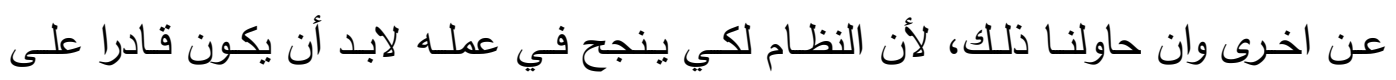
استدعاء كل الاحداث المخزونة فيه وان كانت احداثاً بسيطة او تافهة او مخزية أو احداث مدعاة للفخر والاعتزاز هذه الالية الخاصـة بالذاكرة التي تميزها كآلية عمل هي نفسها التي تسمح لهذه الاحداث البسبطة التي ترافق الحدث الصادم من أن تكون ذكربات مميزة وذات اولوبة في الاسترجاع وبتقصيلات عالية الدقة (Brown \& Kulik, 1977, P. 75) 
وقد تكون هذه الآلية أي تذكر كل الاحداث التي تصاحب الحدث الصادم. ربما تكون آلية بقاء فان الاحداث التي كانت تمر على الانسان سابقا والتي تتطلب منه البقاء على قيد

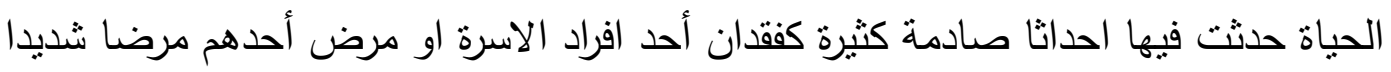

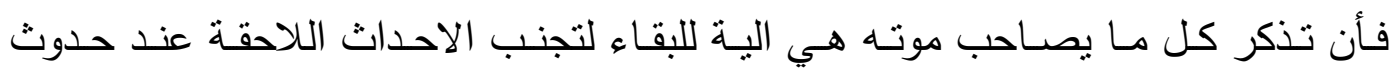

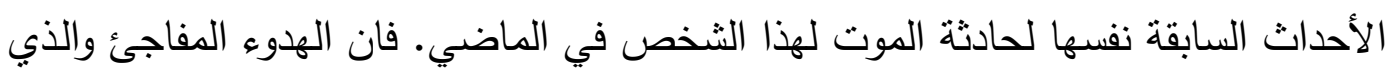

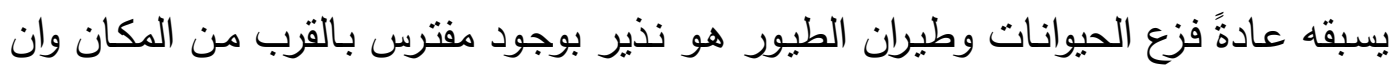

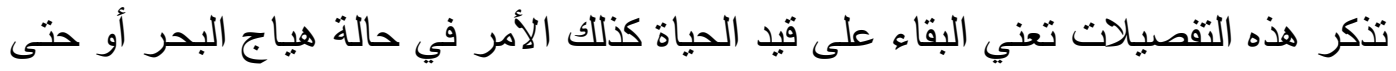

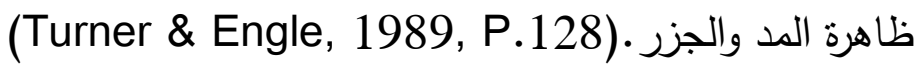
وعلى الرغم من ان ذاكرة الوميض تحتفظ بالأحداث وتفصيلاتها مدة طويلة إلا أنها مع مع الجع

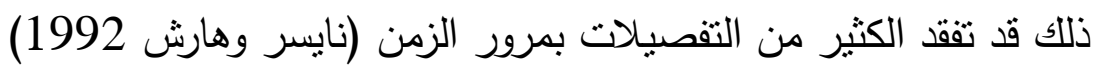
ولكن مع ذلك تبقى الاحداث وتفصيلاتها بشكل كبير في الذاكرة. ويعتقد ان جزءاً كبيراً

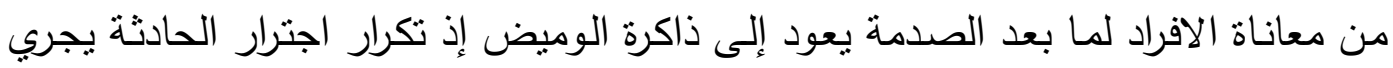

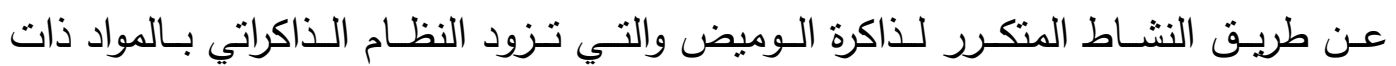
التفصيلات المفزعة وتغذيها بمكملات من أحداث أو أجزاء من أحداث سابقة.

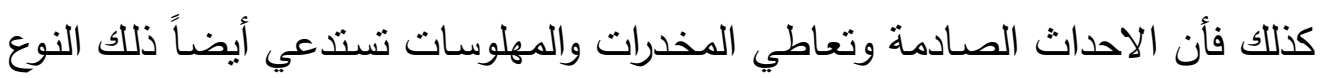
من الذاكرة فأنها تتيح عودة الوميض من تلك الذاكرة إلى مسنوى الوعي. ( Neisser \&) Harsch , 1992 , P.76

في جانب اخر يشبر عدد من الباحثين مثل (ثالاريكو وروبين 2009) إلى أن ذاكرة

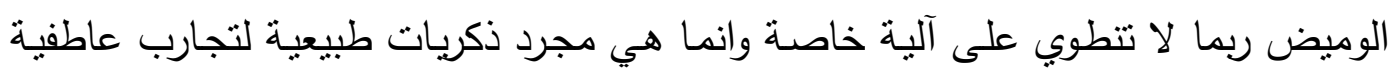

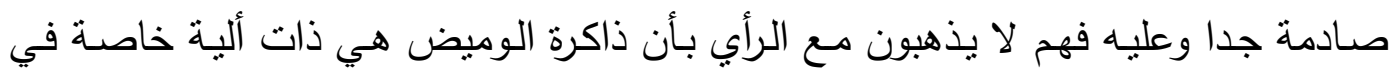
التذكر وانما هي ذكريات مرسخة استتادا إلى طبيعة الانفعال المصاحب لها ضمن عملية

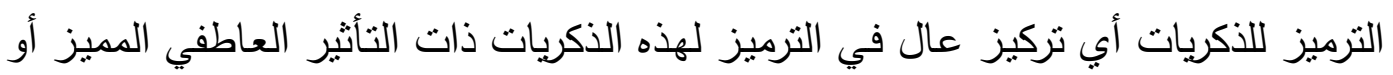

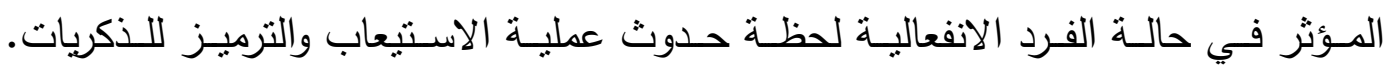

(Talarico \& Rubin, 2009. P. 195)

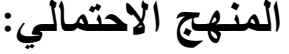

افتزرض اوكسفورد وشاتر (1998) ـ أن المنطق لا يزودنا دائماً بإطار مناسب نستطيع

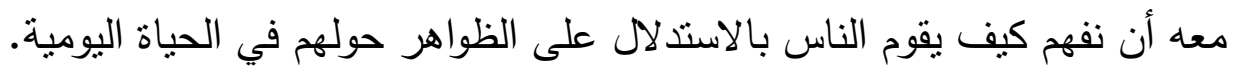

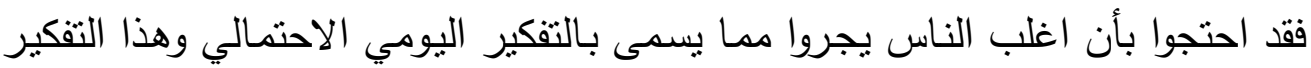

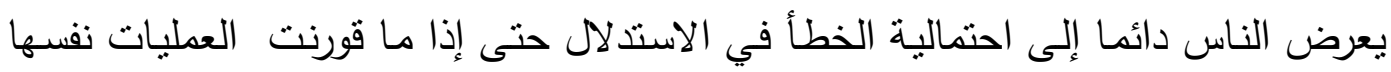

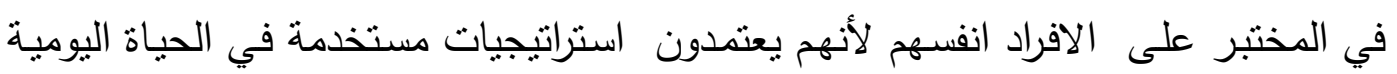


قائمـة اساساً على احكام احتمالية معززة بالخبرة مـع اهمال الفحص الجيد لمعطيات البيئة الواقعية في لحظة اتخاذ القرار أو تكوين الراي بشأن الاحكام. فالنساس تعتمد مـا تعتقده وعلى والخبرات السـابقة وتقيم الاحتمـال بمعنى الاحتمـال

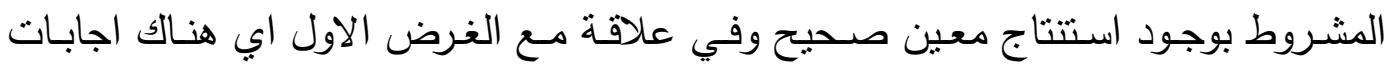

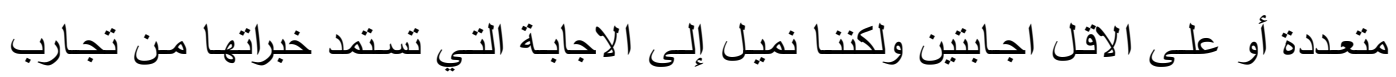

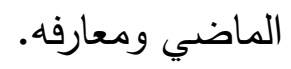
فأن معالجة الاثكالية الاتية تكون معروفة وهي إذا كان أنف جون راثـح للسوائل اذن

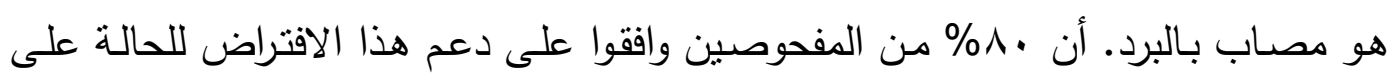

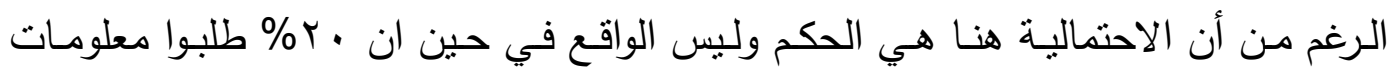

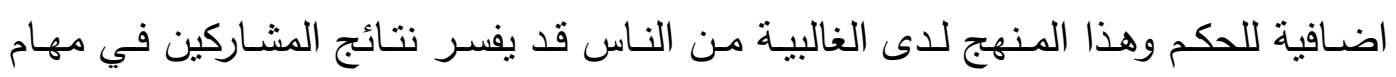

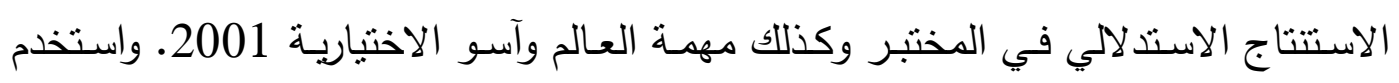
كذللك كبح الثأثيرات الجانبية أو الداخلية والتميزات. (Wason, 2001, P .65)

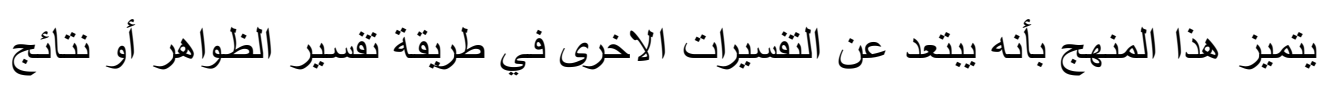

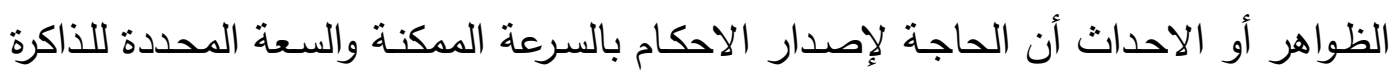

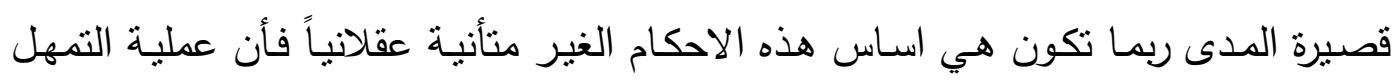

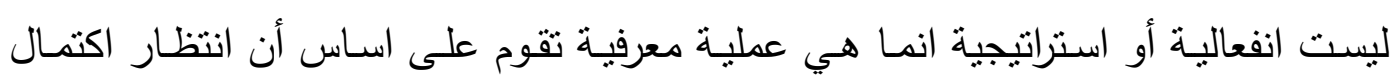

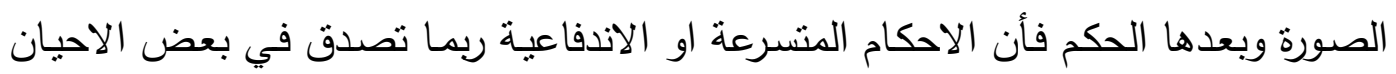

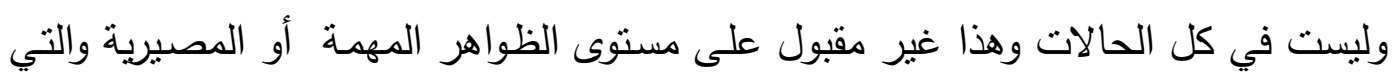

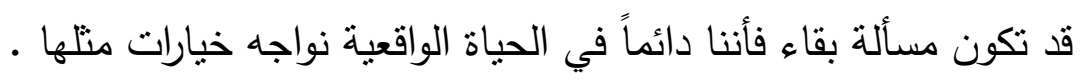

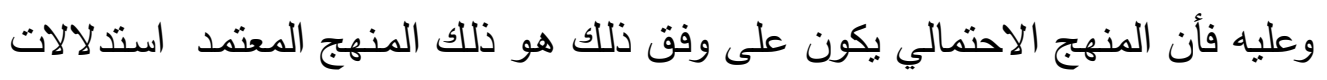

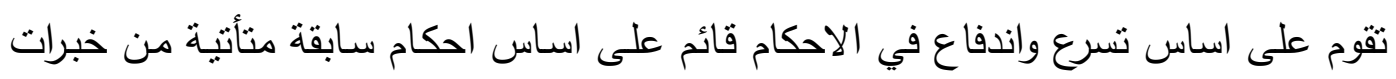

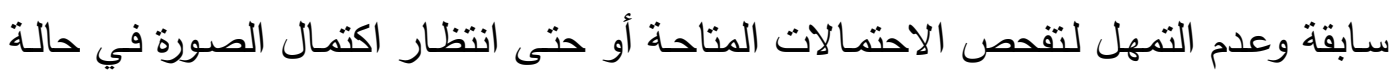
عدم وجود معلومات كافية في وقت اتخاذ القرار . (Neisser, 1967, P. 78)

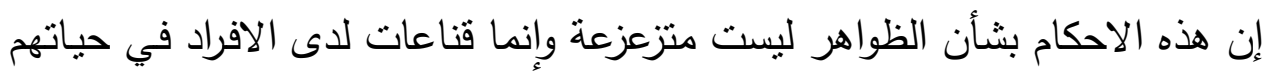

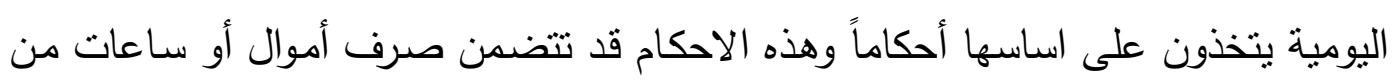

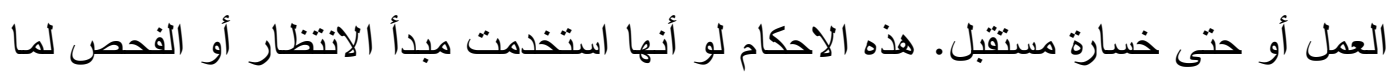

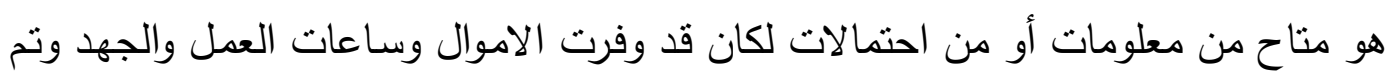
تجنب الفثل والاحباط. (Cohen, 1983, P.54) 
يتفق الجميع بأن التفكير العميق يغطي مجالاً واسعاً من مختلف النشاطات العقلية مثل معالجة الافكار للخروج بأفكار جديدة، التتظير، المحاججة، اتخاذ القرار وحل المشكلات.

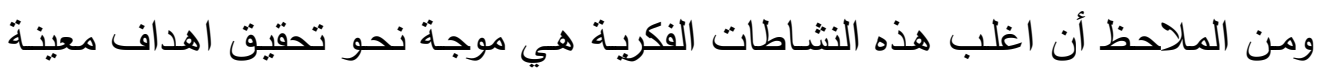

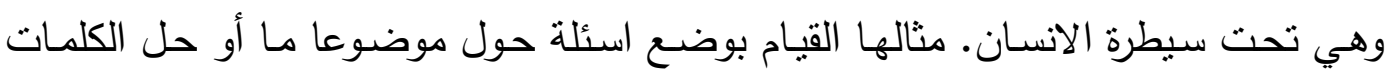
المتقاطعة أو محاولة فهم نظرية علمية تحوي تفصيلات كثيرة نتطلب نشاطاً معرفياً مميزاً.

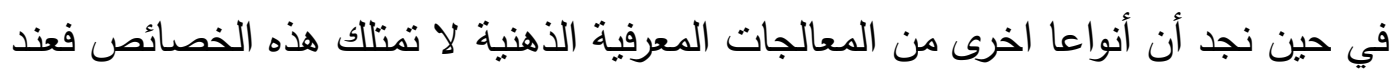

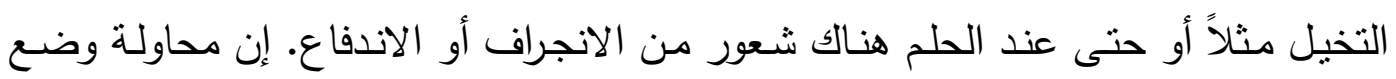
نظرية خاصة لحل المشكلات يجب أن تعالج أو توضح طيف كبير من المعالجات المعرفية

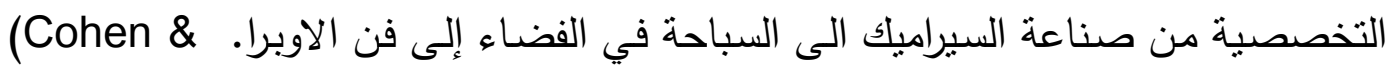

Eichenbaum, 1993, P. 95) الفصل الثالث: إجراءات البحث:

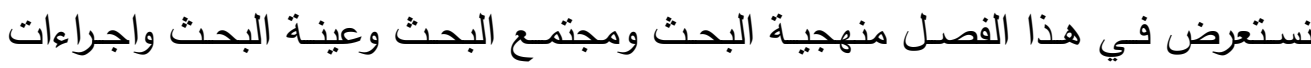
القياس والوسائل الاحصائية التي استخدمت لمعالجة البيانات أحصائياً. اولا: مجتمع البحث:

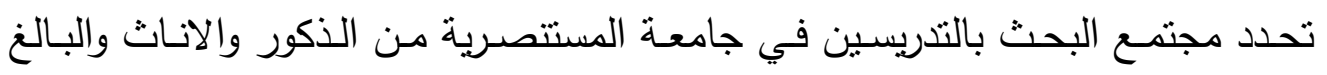
عددهم (3302) وممن كانت لديهم سنوات خبرة أكثر من عندرة سنوات للعـام الدراسي فئي 2020 - 2019 ثانيا: عينة البحث: بلغت عينة البحث الحالي (180) مدرساً ومدرسة في كلية الآداب جامعة المستتصرية. والجدول رقم (1) يوضح ذلك ":- بله الجدول رقم (1) عينة البحث الاساسية موزعة حسب الجنس

\begin{tabular}{|c|c|c|c|c|}
\hline \multirow[t]{2}{*}{ المجموع } & \multicolumn{2}{|c|}{ الجنس } & \multirow[t]{2}{*}{ الكلية } & \multirow[t]{2}{*}{ الجامعة } \\
\hline & \multirow[t]{2}{*}{ الاناث } & \multirow[t]{2}{*}{ الذكور } & & \\
\hline \multirow[b]{2}{*}{180} & & & \multirow[t]{2}{*}{ الآداب } & \multirow[t]{2}{*}{ لمستتصرية } \\
\hline & 90 & 90 & & \\
\hline
\end{tabular}
ثالثا: أداتا البحث:

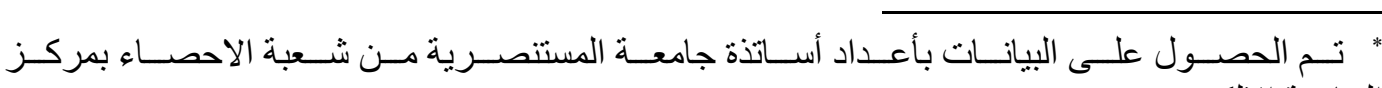
الجامعة الإلكتروني 
تطلب تحقيق اهداف البحث بناء اداتين الاولى لقياس ذاكرة الوميض والثانية لقياس المنهج الاحتمالي وقد جرى ذلك على وفق الخطوات الآتية: 1- التخطيط للمقياسين:

لغرض بناء المقياسين جرى الاطلاع بشكل مفصل على الادبيات السابقة مثل الإطار

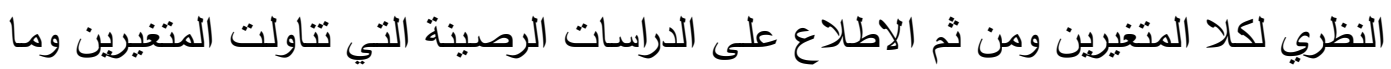
أستطاع الباحث الحصول علية من طرائق القياس ومن المقاييس. r - r - وصف المقياسين: تألف مقياس ذاكرة الوميض من (24) فقرة بعد ان جرى حذف ثنلاث فقرات في أثناء الاجراءات اما مقياس المنهج الاحتمالي فقد تالف من (23) فقرة وقد حذفت قبلها فقرتان في

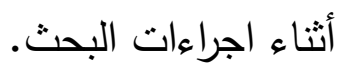

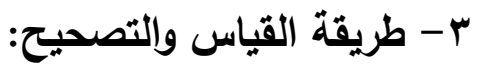
تجري عملية القياس بتوزيع المقياس على السـادة اسـاتذة الجامعة والطلب إليهم قراءة

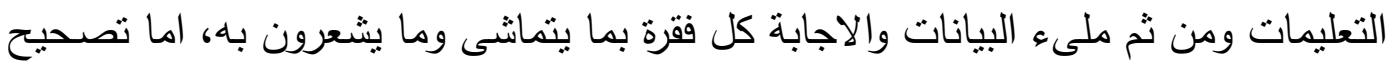

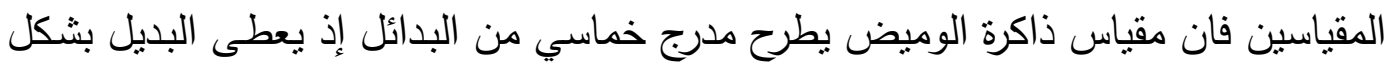

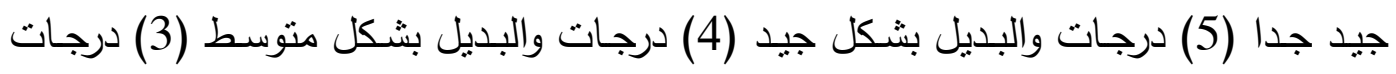
والبديل بشكل بسيط درجتين والبديل بشكل بسيط جدا درجة واحدة. وبذللك فأن اعلى درجة دئل

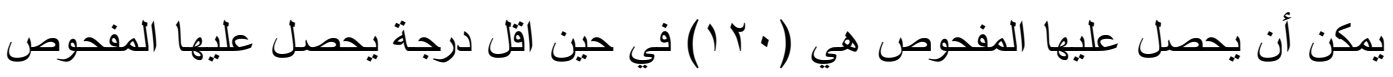

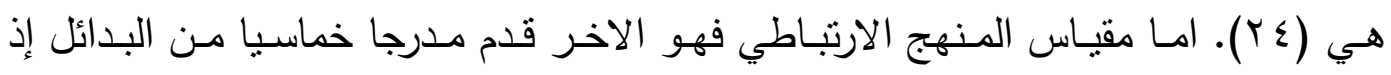

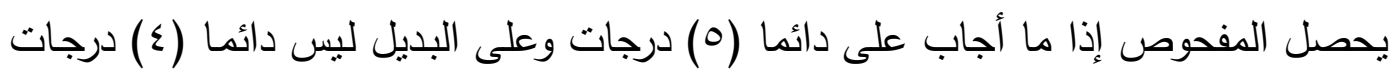
وعلى البديل احيانا (r) درجات والبديل نادرا درجتين والبديل (ابدا) درجة واحدة.

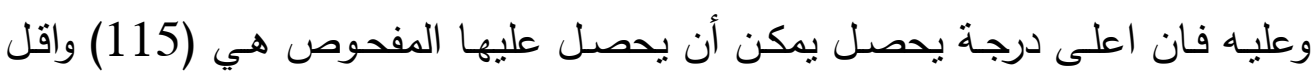

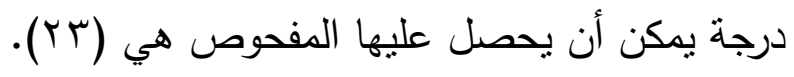

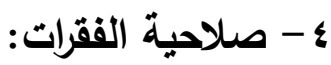

لغرض معرفة صـاحية المقياسين المقترحين قام الباحث بعرض المقياسين المقترحين

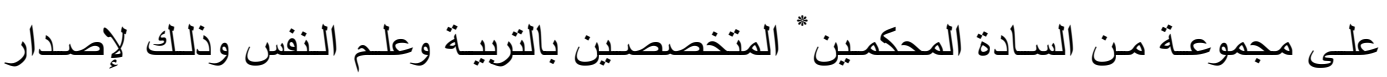

$$
\begin{aligned}
& \text { * اسماء السادة المحكمين حسب أسبقية اللقب العلمي: }
\end{aligned}
$$

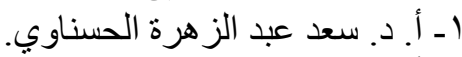

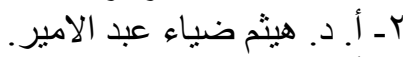

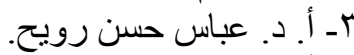

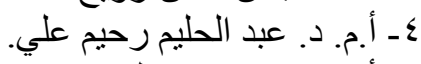

$$
\begin{aligned}
& \text { هـ أ. م. د. حيدر فاضل حسن. } \\
& \text { 7- أ. أ. م. د. نو حيدر فاضل مهدي الطيار. }
\end{aligned}
$$


احكامهم بشان صلاحية الفقرات وطريقة وأسلوب القياس والبدائل المقدمة وفلسفة القياس وقد

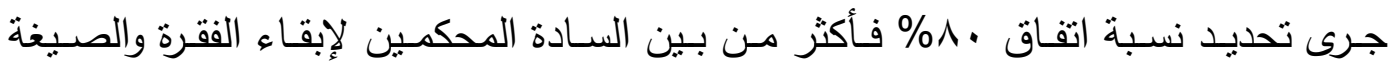
والاسـلوب للمقياسين المعروضين وعلى وفق هذا الاجراء جرى حذف ثنلاث فقرات من مقياس ذاكرة الوميض وفقرة واحدة من مقياس المنهج الاحتمالي وبذلك اصبح المقياس المعد

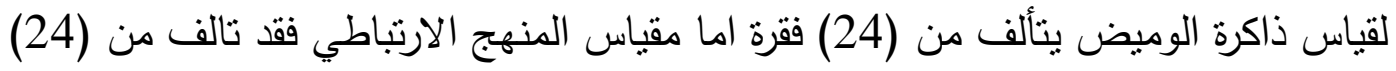
فقرة لغاية هذه المرحلة من البحث.

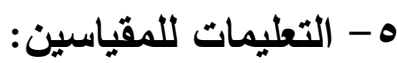

حرص الباحث على أن تكون التعليمات للمقياسين واضحة ومباشرة ودقيقة ومفهومة إذ شرح للمستجيبين طريقة الاجابة وحث العينة على قراءة كل فقرة بعناية كبيرة ومن ثم التأثير

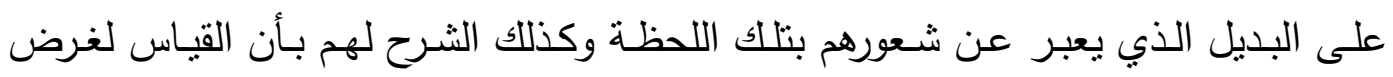
البحث العلمي فقط ولا داعي لذكر الاسم أو أي شيء بدل على شعلى شخصية المستجيب.

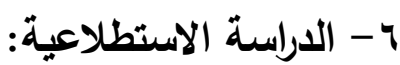

جرى اجراء الدراسة الاستطلاعية لمعرفة مدى وضوح التعليمات وكذللك معرفة صعوبة التهاية الفقرات أو اي غموض فيها والوقت المستغرق للإجابة على المقياسين وقد جرى هذا الاجراء

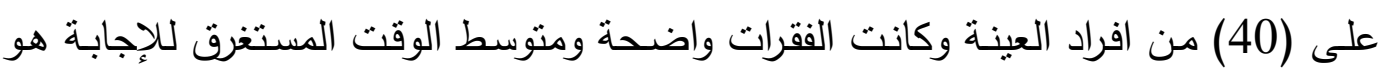
(14) (14) دقيقة. V - التحليل الاحصائي لفقرات المقياسين: استخدم اسلوب المجموعتين المنطرفتين لإيجاد القوة التمييزية لفقرات المقياسية وعلى الإيلى

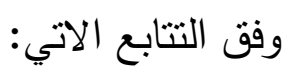
1 - جرى حساب الدرجة الكلية لاستمارات المستجييين والبالغ عددهم (180). r- نرتيب الاسنمارات من اعلى إلى أدني درجة.

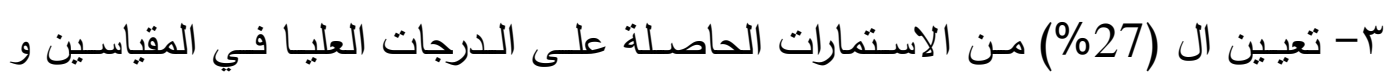
(27\%) من الاستمارات الحاصلة على الدرجات الدنيا.

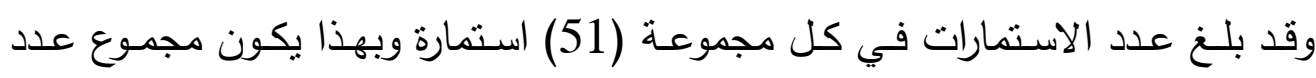

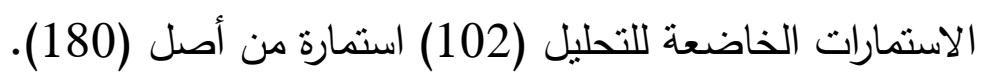

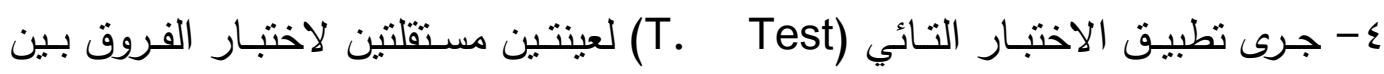
المجموعتين العليا والدنيا وكانت جميع فقرات مقياس ذاكرة الوميض مميزة عند مستوى دلالة

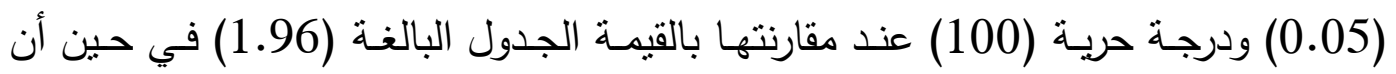
هناك فقرة واحدة فقط حذفت من مقياس المنهج الاحتمالي أما باقي الفقرات فقد كانت مميزة 


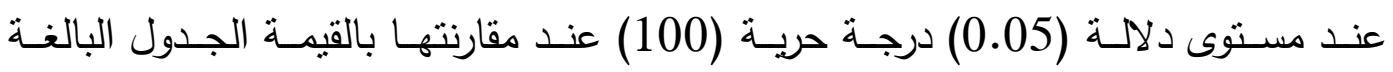

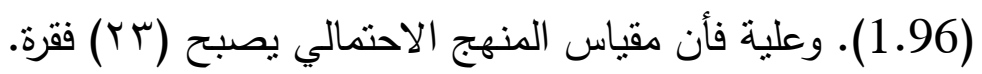

N- مؤشرات صدق المقياس : Validity

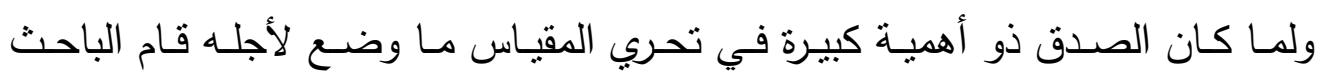

باستخراج نوعين من الصدق للمقياسين هما:

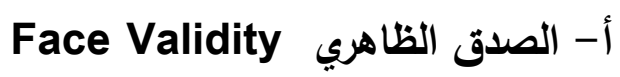

إن الطريقـة المفضـلة للتأكد مـن الصدي الظـاهري هـي أن يقوم عدد مـن المحكمين المختصين بإبداء آرائهم حول مدى كون الفقرات ممثلة للصفة المراد قياسها. وقد تحقق هذا

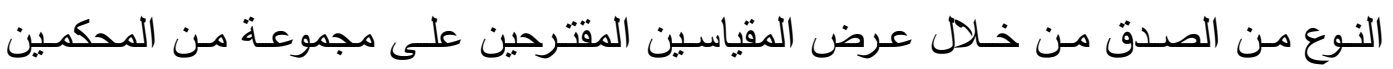
المتخصصين بالتربية وعلم النفس واخذت نسبة اتفاق (80\%) فأكثر كما ذكر في آنفاً.

Construct Validity: بل صدق البناء جرى التحقق مـن هذا الصدق فيمـا يتعلق بالمقياسين المقترحين إذ استخدام معامل ارتباط بيرسون (Person Correlation Coefficient) وجرى استخدام الاختبار التائي لاختبار معامل الارتباط واتضـح ان جيع معاملات الارتباط دالة احصائيا للمقياسين دالة التاني احصائيا عند مقارنتها بالقيمة التائية الجدولية البالغة (196) وبمستوى دلالة (0.05) ودرجة الأبالية حرية (178).

Reliability: مؤثرات الثبات للمقياسين وقد تحقق الباحث من ثبات المقياسين من خلال استخدام الطرائق الآتية:

أ- الثبات بطريقة التجزئة النصفية:

جرى اختبار (40) فردا من العينة لغرض اجراء الثبات بطريقة التجزئة النصفية إذ قسم

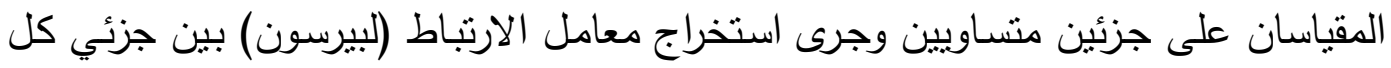
مقياس على حده وقد كان معامل ارتباط مقياس ذاكرة الوميض (0.74) وعند تصحيحه بواسطة استخدام معادلة سبيروان - براون بلغ (0.85) اما مقياس المنهج الاحتمالي فقد بلغ معامل الارنباط (0.71) وعند تصحيحه باستخدام معادلة سبيروان براون فقد بلغ (0.83)

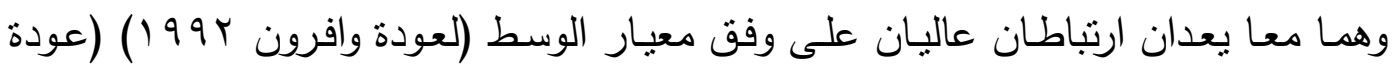

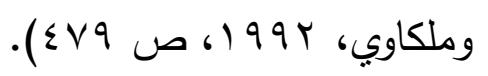

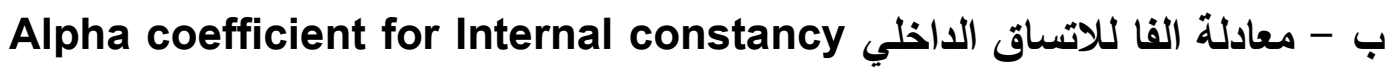
ولحساب الثبات بهذه الطريقة ثم استخدام معادلة الفا على جميع استمارات العينة البالغة (180) استمارة وبعد تطبيق المعادلة بلغ الثبات لمقياس ذاكرة الوميض (0.79) ويعد هذا مئف 
ثباتا عاليا على وفق معيار الفا للثبات، أما مقياس المنهج الاحتمالي فقد بلغ (0.77) ويعد

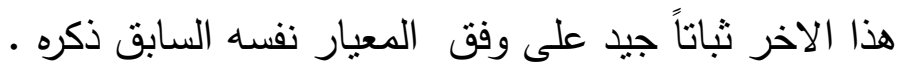

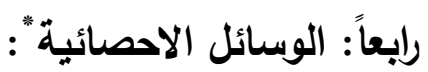

1- الاختبار الثائي لعينة واحدة (T. Test for one Sample) استخدم لمعرفة دلالة الفرق الاحصائية بين المتوسط الفرضي والمنوسط الحسابي للمقياسين.

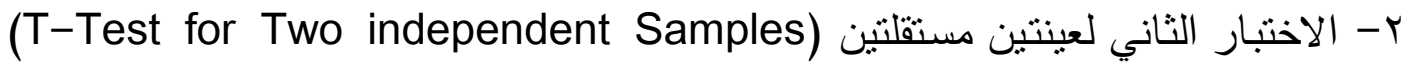
استخدم الاختبـار لاسـتخراج القوة التمييزيـة للفقـرات بأسـلوب المجمـوعتين المتطـرفين

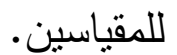
r- معامل ارتباط بيرسون (Pearson carnation coefficient) وقد استخدم لاستخراج

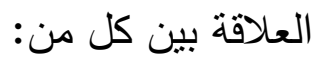
أ- لاستخراج الثبات بطريقة التجزئة النصفية. ب- لاستخراج صدق البناء. ج - ايجاد العلاقة الارتباطية بين ذاكرة الوميض وبين المنهج الاحتمالي لاءى عينة البحث. ع - معادلة سبيرمان - براون (Spearman -Brown formula) وقد استخدت لتصحيح معامل ارتباط بيرسون، مؤشر الثبات للمقياسين. Alpha coefficient for Internal معادلة ألفا كرونباخ للإنسان الداخلي. consistency

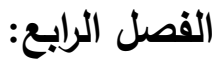
سيتم في هذا الفصل عرض النتائج وتفسيرها ومناقتنها والتوصيات والمقترحات: اولا: عرض النتائج وتفسيرها ومناقثتها: الهلف الاول: معرفة ذاكرة الوميض لاى عينة البحث:

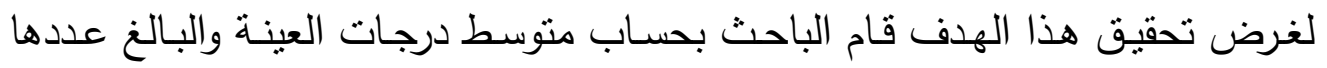

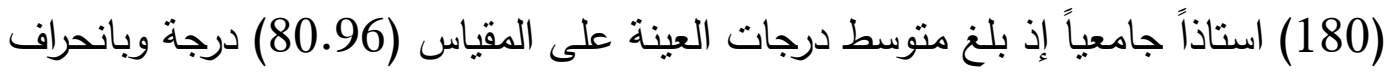

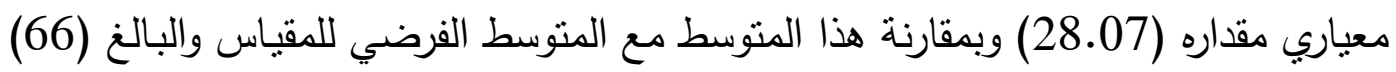

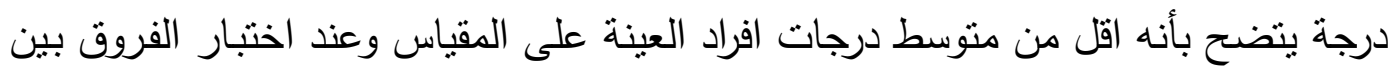

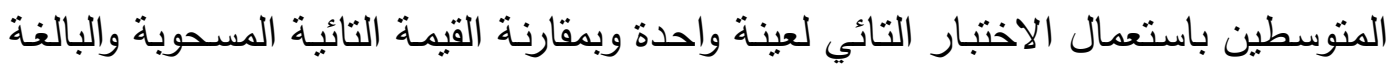
(3.243) بالقيمة التائية الجدولية البالغة (1.96) عند مستوى دلالة (0.05) وبدرجة مرية

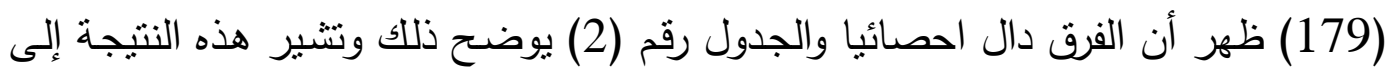
أن اساتذة الجامعة لديهم ذاكرة وميض جيدة والجدول رقم (2) يوضح ذللك. 
الجدول رقم(r)نتائج الاختبار التائي لعينة واحدة للفرق بين المتوسط الفرضي والمتوسط الحسابي لعينة البحث

\begin{tabular}{|c|c|c|c|c|c|c|}
\hline الاحصائة الاية & القيمة التائية & القيمة التائية & المترضط & الانحراف & الحسابي & العينة \\
\hline 0.05 & 1.96 & 3.343 & 66 & 28.07 & 80.96 & 180 \\
\hline
\end{tabular}

وبـالرجوع الـى نظريـة (بـروان وكوليك 9VV I ) يبدو ان الافراد يعـالجون اللحظـة التي يحصـل بها الحدث المهم أو الصـادم بكل مـا فيه مـن تفاصسيل بغض النظـر عن أهميـة التفصيلات تلك فهي تعالج بعمق وترمز بدقة لأنها ضمن السباق (تسلسل أحداث) العام لحدوث الحدث ألاهم أو الأكثر تأثيراً في تلك اللحظة ومن ثمّ استرجاع الحدث يعني كل التقصيلات الصـيرة معسه وان كانت احداثا يوميـة غير ذات أهميـة بحد ذاتهـا فـأن القيـام بالمشي في حديقة المنزل أو السير بالثارع لبس بالحدث المهم أبداً ولكن الحدث الذي يربط هـذه الاحداث وعمـق ذلك المنبـه وشـدته جعلت الفـرد يكون صـورة كليـة لكل الاحـداث المصاحبة وربما هنالك عامل آخر وهو التراتب أو التتابع الضروري للاسترجاع فأن الافراد يتذكرون بشكل متسلسل كل شيء أو لكل العناصر وعليه فان الحدث هو ضمن سلسلة او تتابع حدثي مهم وأن العنصر المهم، أو الثديد التنبيه يجب أن ينضم إلى تلك السلسلة من الاحداث المتتابعة وايضا يجب أن يسترجع النظام المعرفي كل الاحداث المهمة وما يحيط بها لغرض النجاح في عملية الاسترجاع فهذه تعدُّ مهمة اساسية للنظام المعرفي ومهمه في مسألة البقاء. فأن تنلسل الاحداث ينبأ بحدث ما وهو قد يكون مفصلياً في مسألة تجنب الخطر المحدق وهناك عامل التبيه العصبي الذي يغذي الذاكرة دائما بوسـائل السيطرة على البيئة فاسترجاع التقصيلات المصاحبة هو تذكر توكيدي للحدث لأغراض التيقن والتقريق. الهرف الثاني: معرفة المنهج الارتباطي لاى عينة البحث: قـام الباحث بحسـاب متوسط درجـات افراد العينـة البالغـة (180) اسـتاذا جامعبـا مـن الذكور والانـات حإذ بلـن متوسط درجات العينـة على المقياس (65.02) بـانحراف معياري مقداره (22.74) وبمقارنة المتوسط الفرضي البالغ (72) يتضتح بان المتوسط الحسابي اقل من المتوسط الفرضي وعند اختبار الفرق بين المتوسطين باستخدام الاختبار التائي لعينة واحدة وبمقارنة القيمة النائية المحسوبة والبالغة (2.822) بالقيمة الجدولية البالغة (1.96)

$$
\text { عند مستوى دلالة (0.05). }
$$

وبدرجة حرية (179) ظهر ان الفرق غير دال احصـئيا والجدول رقم (3) يوضـح ذلك وتشير هذه النتيجة ان اسـاتذة الجامعة لا يقومون بشكل واسـع باتباع المنهج الاحتمـالي في التفكير 
(3) الجدول رقم (3)

الاختبار التائي لعينة واحدة للفرق بين المتوسط الفرضي والمتوسط الحسابي للعينة

\begin{tabular}{|c|c|c|c|c|c|c|}
\hline الاحصائية & القيمة التائية & القيمة التائية & الفرضي المتوسط & الانحراف المعياري & الحسابي & العينة \\
\hline 0.05 & 1.96 & 2.822 & 72 & 22.74 & 65.02 & 180 \\
\hline
\end{tabular}

وفي هذا الصدد يشير كل من (اكسفورد وشاتر 1998) إلى أن الافراد بشكل عام لا يقومون بفحص الاحتمالات من حولهم وانما يعتمدون الخبرات لتفسير الظواهر من حولهم، ويبدو أن الاساتذة الجامعين يقومون بأنماط من الاستدلال القائم على فحص البئئئة (والذاكرة

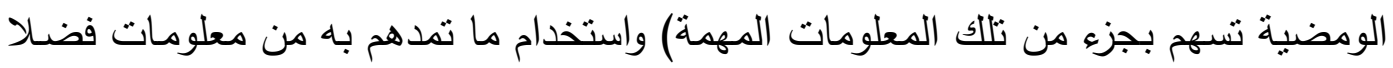

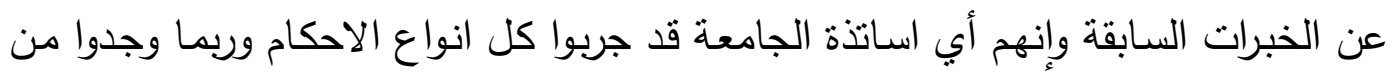

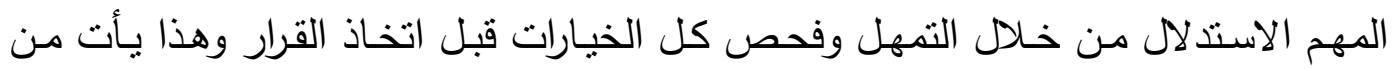

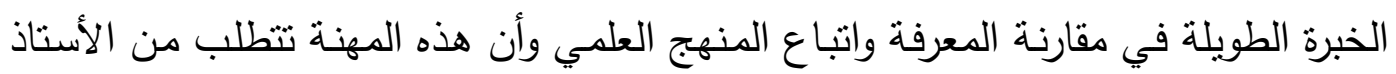

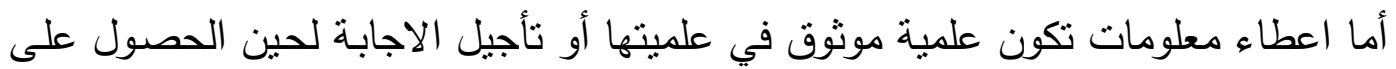
المعلومة الصحيحة فضلا عن مستواهم العلمي وقدتهم على اجراء تفكير معقد وليس بسيط لما يجري حولهم من احداث ويبدو انهم لا يتسرعون في اطلاق الاحكام وينتظرون قليلا

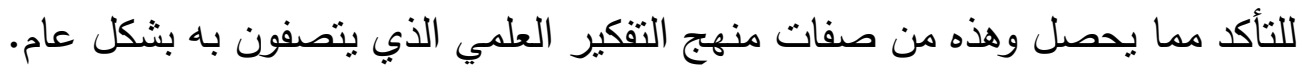
الهلف الثالث: معرفة العلاقة بين ذاكرة الوميض والمنهج الارتباطي لاى عينة البحث.

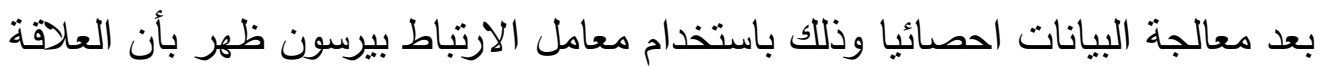
بين ذاكرة الوميض والمنهج الارتباطي قد بلغت (-0.181) والقيمة التائية لمعامل الارتباط

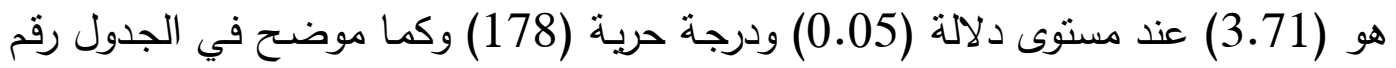

الجدول رقم(4) العلاقة الارتباطية بين ذاكرة الوميض والمنهج الاحتمالي

\begin{tabular}{|c|c|c|c|c|}
\hline \multirow[t]{2}{*}{ مستوى الدلالة } & \multicolumn{2}{|c|}{ القيمة التائية } & معامل الارتباط بين ذاكرة & العدد العد \\
\hline & الجدولية & المحسوية & الوميض والمنهج الارتباطي & \\
\hline 0.05 & 1.96 & 3.71 & $0.181-$ & 180 \\
\hline
\end{tabular}

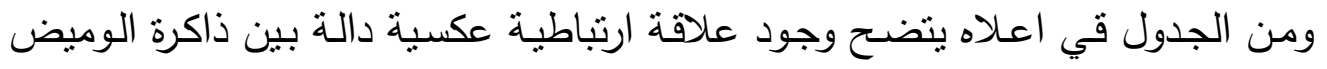

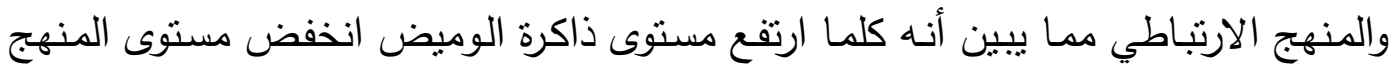

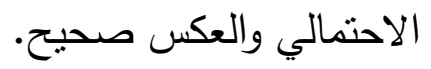


ويرجع سبب ذلك إلى أن الاسـاتذة الجامعيين لديهم ذاكرة وميض جيدة جدا وهو ربما

يكون بحكم كثرة الخبرات المكتسبة عبر مسيرة التعليم الطويلة والتي كانت تتطلب في كل مرحلة مستوى عال من الذاكرة الجيدة في عملية التذكر والمذاكرة وكذلك أن تطور النظام المعرفي للفرد يتيح لـه تذكر افضـل للتفصيلات وإن الاسـاتذة الجـامعيين وبحكم عملهم يحتاجون إلى تدريب ذاكرتهم باستمرار والحفاظ عليها في وضـع متيقظ دائمـا امـا المستوى المتدن في المنهج الاحتمالي فهو يعود إلى أنهم أيضا بحكم عملهم مبالين إلى التأكيد والتأكد من المعلومات قبل تبنيها إذ إن الاساتذة اظهروا تمهل وفحص لكل البدائل قبل اتخاذ القرار فهم لا يعتمدون تماما الخبرات في الكثف عن الظواهر المتثابهة في الحياة الطبيعية وعلية فان اعتمـاد المنهج الاحتمـالي لا يتعلق بنمط الذاكرة الومضية للأحداث بـل بنوع التخزين وعمق المعالجـة ، فان التفكير العلمي الذي عادة مـا يتبعهـ ألأسـاتذة الجامعيون يهنم كثيراً بالتفصيلات والتي تعني ضمن ما تعني التفريق بين العناصر في البيئة وان كانت متقاربة أو متثنابهة وهو جوهر التخصص الذي يعني التفريق والدراسة المعدقة لكل جزئية من الجزئيات

للكل المعروف. ثانيا: التوصيات:

في ضوء النتائج خرج البحث الحالي بعدد من التوصيات وهي: 1- استعمال تقنية ذاكرة الوميض لدى الطلبة في كافة المراحل في ربط تفصيلات المواد العلمية المهمة والمادة العلمي الاكثر أهمية. r- الاستفادة من هذا النمط من انماط الذاكرة في ايجاد أفكار جديدة داخل الصف الدراسي إذ ربط المواد بانفعال ما لغرض التذكر الاسهل. ب- اسـتغلال دور تذكر التفصيلات لغرض تـكر الصـيغ الكليـة في أنتـاء القيـام بتذكر الاحداث على مستوى الافراد. ـ- التأكيد على أن للأحداث الواقعية اسباب واقعية قد لا تكون ما نعتقده نحن وتطبيقات ذلك في المعاهد العلمية واماكن اتخاذ القرار منل المحاكم وغيرها. 0- حث الطلبة في المدارس والجامعات على اتباع منهج تفكير قائم على فحص الاسباب وليس اتخاذ قرار او حكم من تصورات قائمة على خبرات الماضي.

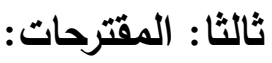

خرج البحث الحالي بعدد من المقترحات لبحوث مستقبلية: 1- اجراء دراسة ميدانية لعلاقة ذاكرة الوميض بنمط الثخصية (B او A). r- اجراء دراسة ميدانية لعلاقة ذاكرة الوميض بالذاكرة الصورية. r- اجراء دراسة ميدانية لدراسة علاقة ذاكرة الوميض بقلق المستقبل. 


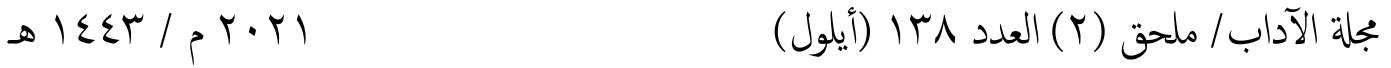

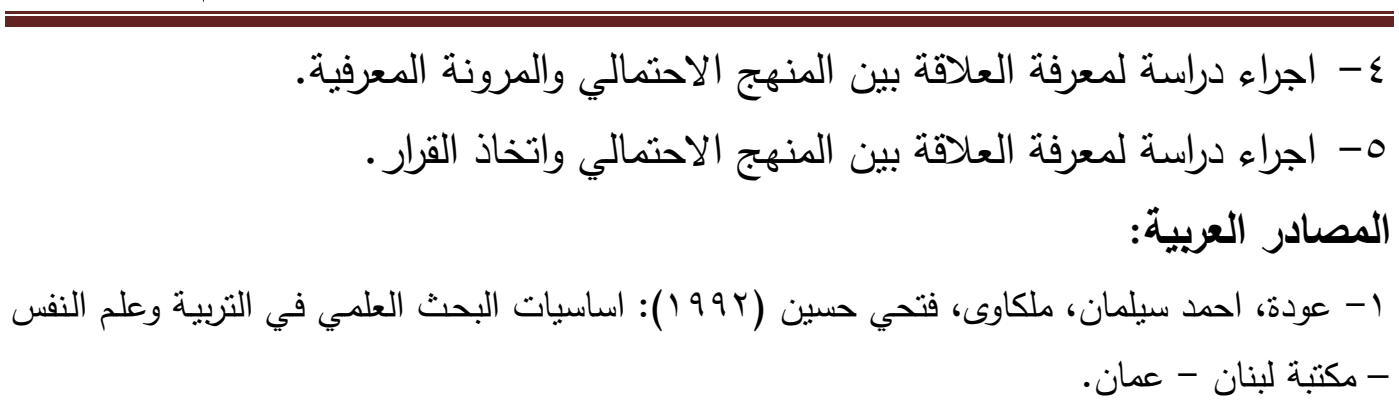

\section{References:}

- Baddeley, A. (2003): " The handbook of Memory Disorders " J. of wiley, New York.

- Brown, R.\& Kulik, J. C (1977)." Flashbulb Memories Cognition", 5, 73, 99.

- Cohen, G. (1983):" the Psychology of Cognition" 2nd ed, London, Academic Press.

- Cohen, N.J and Eichenbaum H, E. (1993): Memory Amnesia and the Hippocampal. system Cambridge, MA, IT, Press.

- Davidson, P.S.R. \& Glisky, E.L. (2002)." Is Flashbulb memory a special instance of screen memory" Evidence from older adults' memory, 10, 99. 111.

- Gardner, M. B. (2000): " Problem of localization in the median plane: Effect of pinnae cavity. " J. of the Acoustical Society of America, 90, 400- 400.

- Martin, R.C. (1993): " Short-term memory and sentence processing: Evidence from neuropsychology." memory and Cognition, 21, 176-183.

- Neisse, U. (1967). "Cognitive Psychology ". New York Appleton - Century Crofts.

- Neisser, U. and Harsch, N. (1992) "Phantom Flashbulbs: False connections of hearing the news about challenger". In E. Winograd and U. Neisser (eds) Affect and Accuracy in Recall: Studies of flashbulb memories. New York Cambridge university press.

- Oaksford, m. \& Chater, n. (1998): " Rationality in an uncertain World; Essays on the cognitive science of Human Reasoning", Hove; Psychology

- Richmond, J \& Nelson, C.A (2007): "Accounting for Change in declarative memory A cognitive neuroscience Perspective", Developmental Review 27, 349 $-373$.

- Talarico, J. M, \& Rubin, D. G, (2009): " Flashbulb memories result from ordinary memory Processes and extraordinary event characteristics New Issues and Perspectives". Hove Psychology Press.

- Talarico, J, m, and Rubin, D, G. (2003). "Confidence, not Consistency, characterizes flashbulb memories, J. of Psychological Science, 14, 455, 461.

- Turner, M, L. \& Engle, R.W (1989): "Is working memory Capacity Task Dependent", J of memory and Language 28. 127 - 154.

-Wason, P. C. (2001): "Reasoning about a rule" J, Experimental Psychology, 23, $63,71$. 


\title{
ملحق (1)
}

\section{مقياس ذاكرة الوميض بصورته النهائية}

$$
\text { تحية طيبة............... }
$$

بين يديكم مجموعة من الفقرات التي تتحسس طيفاً نفسياً متعلقاً بالذاكرة ارجو من

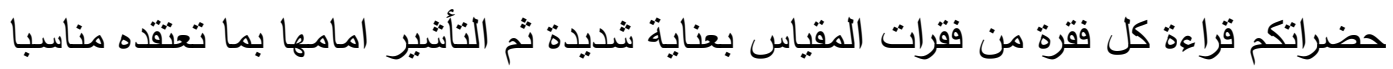

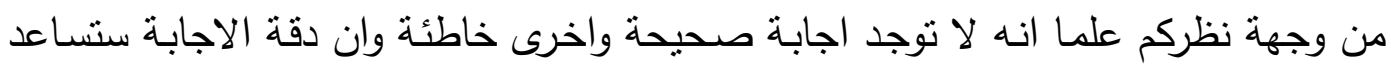

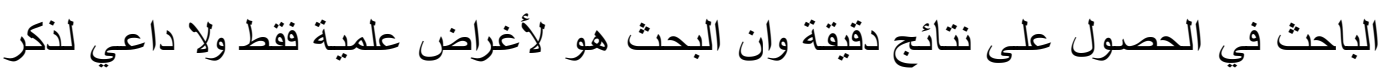
الاسم. يرجى منكم قبل البدء بالإجابة تدوين المعلومات العامة في ادناه.

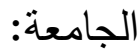 \\ الكلية:

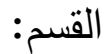 \\ اخر شهادة حصلتم عليها: \\ عدد سنوات الخدمة في الجامعة: \\ الحالة الزوجية:

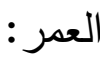 \\ ش ت بكرا جزيلا
}




\begin{tabular}{|c|c|c|c|c|c|c|}
\hline بشيط جدا & 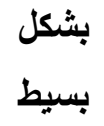 & متوسط بشل & بشكل & جيد جـل & الفقرات & $ت$ \\
\hline & & & & & تقتصنيلات دقيقة. ليلـة زفـافي بكل مـا فيهـا مـن & -1 \\
\hline & & & & & أتذكر لحظة اعلان الرئيس الامريكي & $-r$ \\
\hline & & & & & 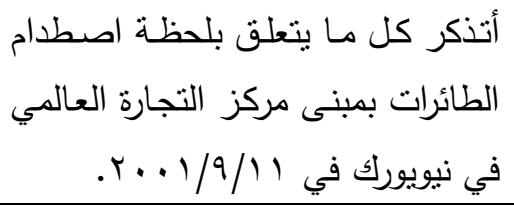 & r \\
\hline & & & & & 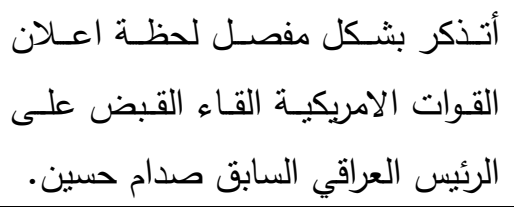 & $-\varepsilon$ \\
\hline & & & & & 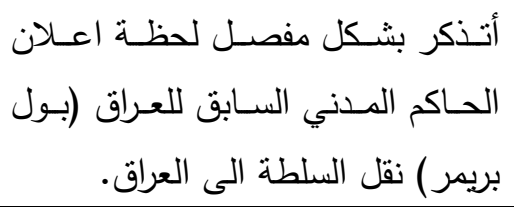 & -0 \\
\hline & & & & & 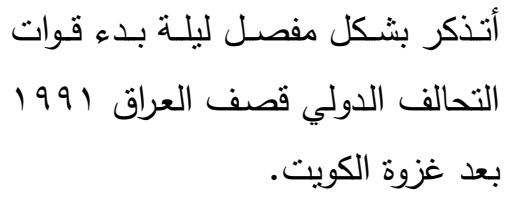 & -7 \\
\hline & & & & & 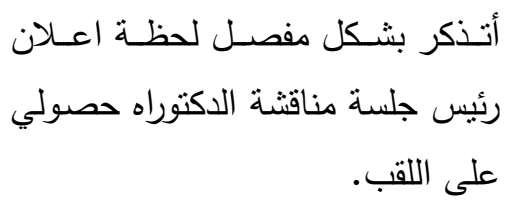 & $-V$ \\
\hline & & & & & 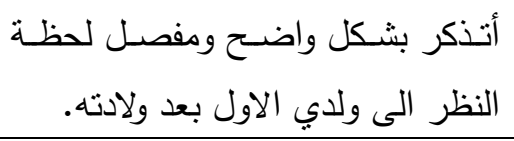 & $-\lambda$ \\
\hline & & & & & 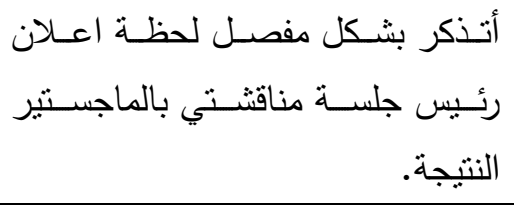 & -9 \\
\hline & & & & & 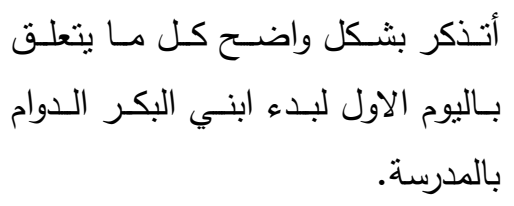 & -1. \\
\hline & & & & & 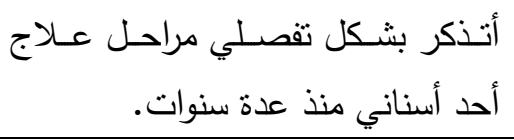 & -11 \\
\hline & & & & & 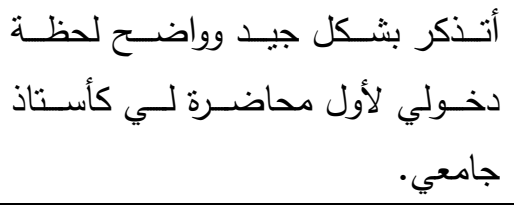 & $-1 T$ \\
\hline
\end{tabular}


مجلة الآداب/ ملحق (ז) العدد مبا (أيلول)

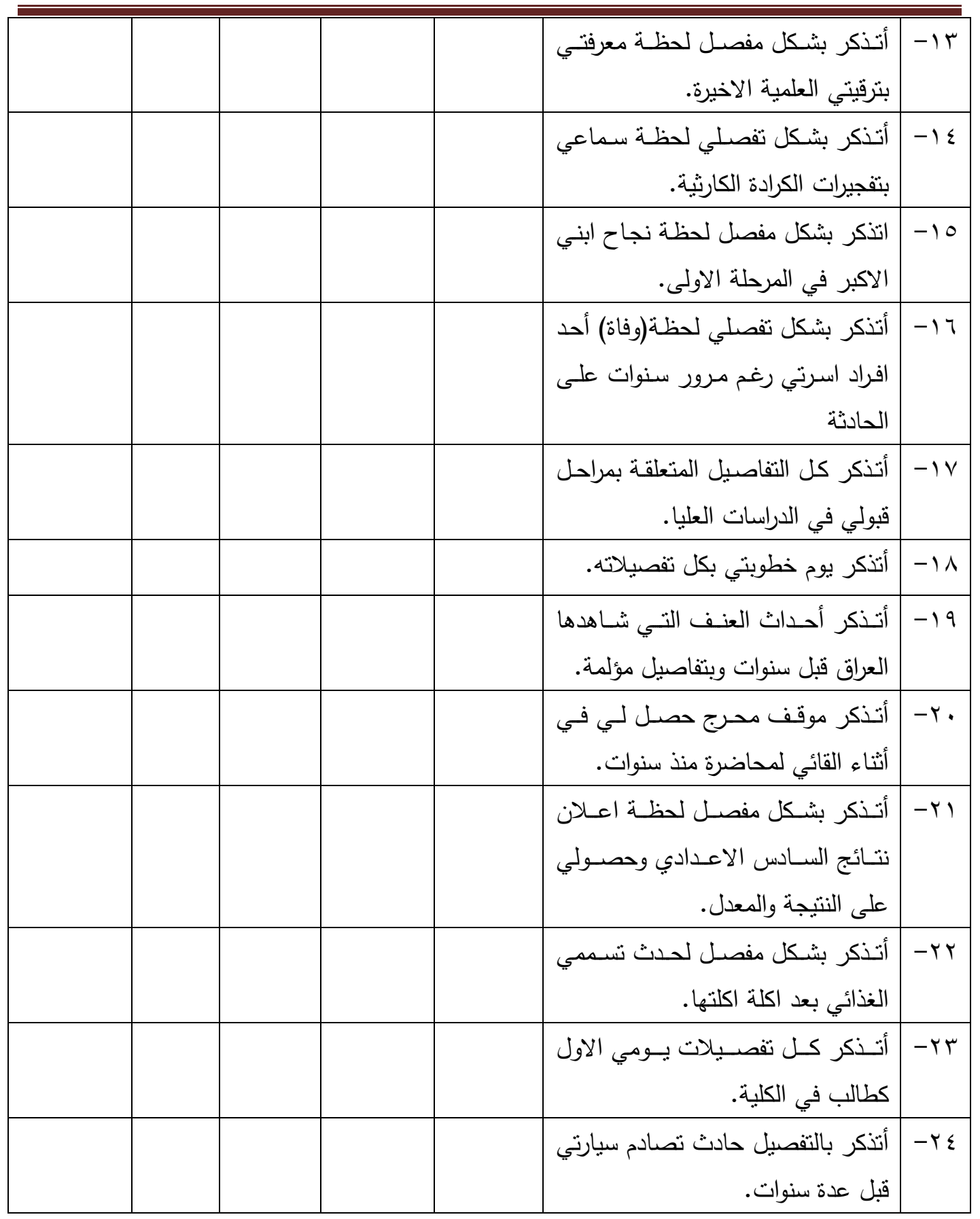




\section{ملحق (r)}

\section{مقياس المنهج الاحتمالي بصورته النهائية}

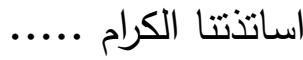
تحية طيبة .... - ت

بين يديكم مجموعة من الفقرات لقياس متغير نفسي متعلق بمنهج للتفكير • ارجو من حضرتكم قراءة كل فقرة من فقرات المقياس بعناية فائقة ثم التأثير امام كل فقرة بما تعتقده

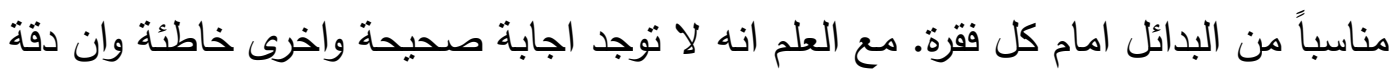

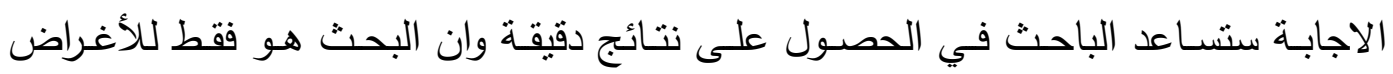
العلمية ولا داعي لذكر الاسم. برجى منكم قبل البدء بالإجابة تدوين المعلومات العامة في ادناه.

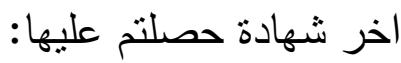

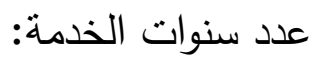

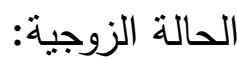

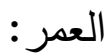

شكرا جزيلا لكم 


\begin{tabular}{|c|c|c|c|c|c|c|}
\hline ابدا & 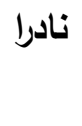 & 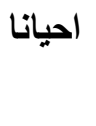 & الاغلب على & 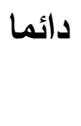 & 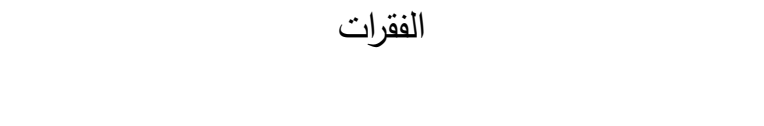 & $ت$ \\
\hline & & & & & أن الاحتمالات تلعب دورا اساسيا في تفكيري وسلوكي. & -1 \\
\hline & & & & & اضع دائماً الاحتمالات السلبية لاي حدث يقع. & $-r$ \\
\hline & & & & & حاجة لفحص استخدم خبراتي السابقة للحكم على الاحداث الواقعية دون & $-r$ \\
\hline & & & & & الاحداث تتكرر دائما هذا مبدأ أؤمن به. & $-\varepsilon$ \\
\hline & & & & & للأحداث. احكم بالاحتمـال دائمـا افحص ثم اضـع الاحتمـالات & -0 \\
\hline & & & & & اعتقد ان احدى سلبياتي هي التسرع بالحكم دون تروي. & -7 \\
\hline & & & & & دائما ما كان الحكم بالاحتمالات يؤدي بي الى الصواب. & $-V$ \\
\hline & & & & & 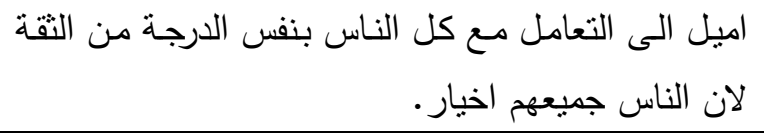 & $-\wedge$ \\
\hline & & & & & ميالين لكسر الروتين. دائماً يكررون سلوكيات معينة لأنهم بطبيعتهم غير & -9 \\
\hline & & & & & أصلـ الى الاستــلال من خـلال مؤشـرات أحدها خبراتي & -1 \\
\hline & & & & & 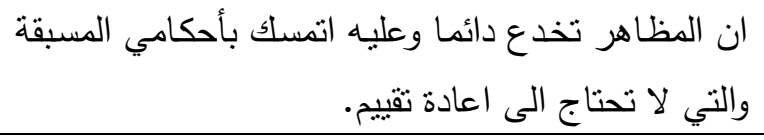 & -11 \\
\hline & & & & & 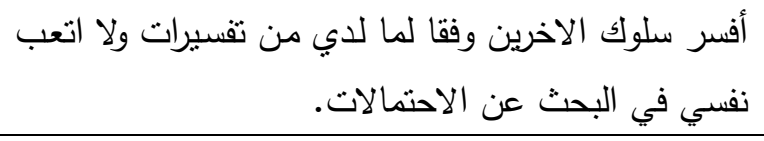 & -14 \\
\hline & & & & & الحكم المطلق هو ظلمع احتمـالات لتصـرفات المحيطين بـي فأحيانـا & -14 \\
\hline & & & & & لكبس كل مـا نعتقده حقيقي فأن العالم مليء بالمفاجئات & $-1 \leqslant$ \\
\hline & & & & & اعتقد انتـي أسـنطيع ان انجـح بالقيـام بوظيفـة (التحـري & -10 \\
\hline & & & & & وخاض معي تجارب عدة اي فكرة عن طبيعة انسان الا إذا كان مقربا مني & -17 \\
\hline & & & & & صرعات نفسية معهم. الابتعاد عن الناس غنيمة تبعدني عن خوض & $-1 \mathrm{~V}$ \\
\hline
\end{tabular}




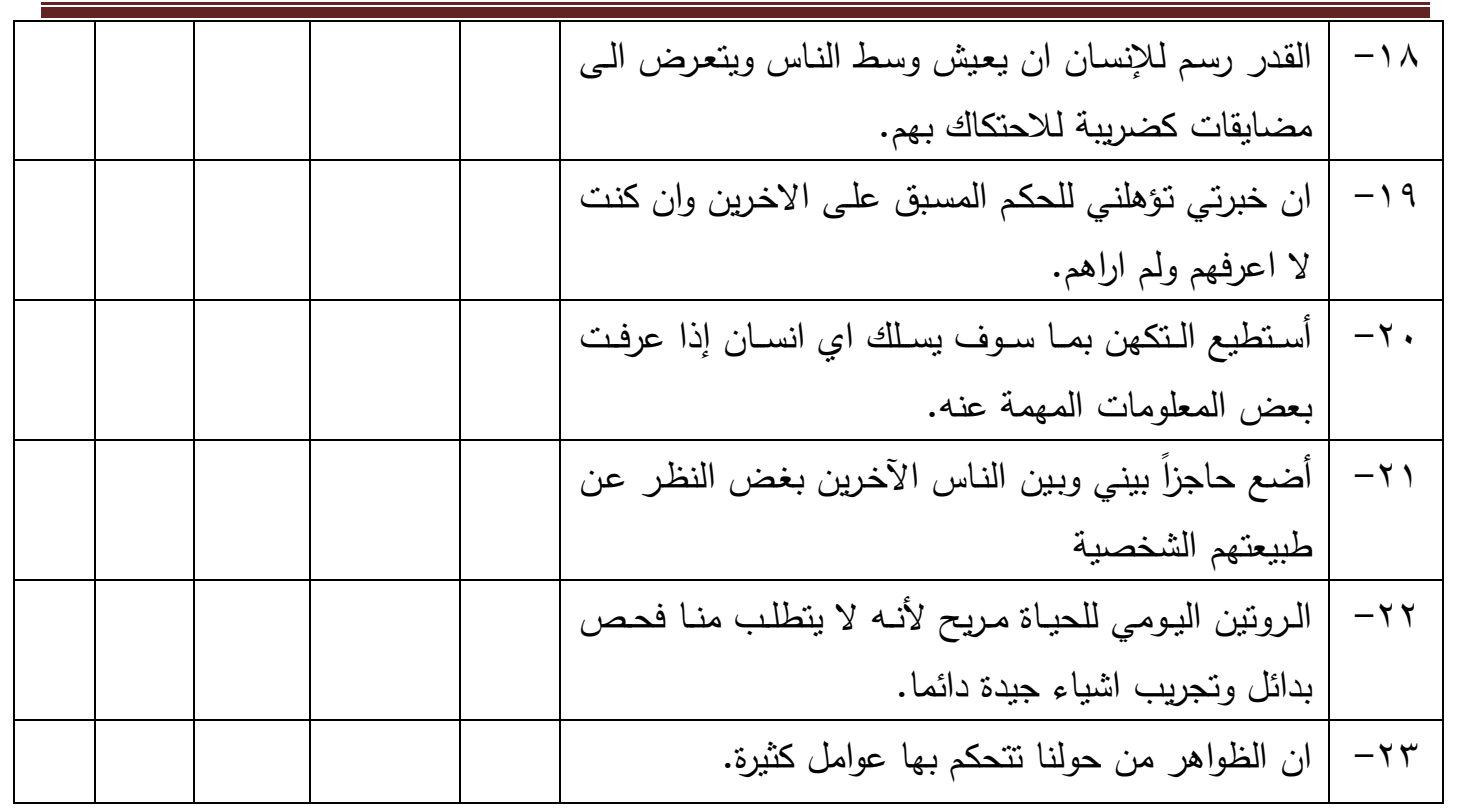

